\title{
Survival after repeated surgery for lung cancer with idiopathic pulmonary fibrosis: a retrospective study
}

\author{
Seijiro Sato ${ }^{1 *}$, Yuki Shimizu', Tatsuya Goto ${ }^{1}$, Akihiko Kitahara', Terumoto Koike' ${ }^{1}$, Hiroyuki Ishikawa²,
} Takehiro Watanabe ${ }^{3}$ and Masanori Tsuchida ${ }^{1}$

\begin{abstract}
Background: Patients with idiopathic pulmonary fibrosis (IPF) have a high risk of developing lung cancer, but few studies have investigated the long-term outcomes of repeated surgery in such patients. The purpose of this study was to evaluate the surgical outcomes of repeated lung cancer surgery in patients with IPF.

Methods: From January 2001 to December 2015, 108 lung cancer patients with IPF underwent pulmonary resection at two institutions; 13 of these patients underwent repeated surgery for lung cancer, and their data were reviewed.

Results: The initial procedures of the 13 patients were lobectomy in 8, segmentectomy in 2, and wedge resection in 3 . The subsequent procedures were wedge resection in 10 and segmentectomy in 3. The clinical stage of the second tumor was stage IA in 12 and stage IB in 1. Postoperatively, 3 patients (23.1\%) developed acute exacerbation (AE) of IPF and died. The rate of decrease in percent vital capacity was significantly higher in patients with AE than in those without $\operatorname{AE}(p=0.011)$. The 3-year overall survival rate was $34.6 \%$. The causes of death were cancer-related in 7, AE of IPF in 3, and metachronous lung cancer in 1.

Conclusions: Despite limited resection, a high incidence of AE was identified. The early and long-term outcomes of repeated surgery in lung cancer patients with IPF were poor because of the high risk of AE of IPF and lung cancer recurrence. Long-term intensive surveillance will be required to determine whether surgical intervention is justified in patients with multiple primary lung cancers and IPF.
\end{abstract}

Keywords: Lung cancer, Idiopathic pulmonary fibrosis, Repeated surgery, Acute exacerbation, Percent vital capacity

\section{Background}

The incidence of lung cancer is higher in patients with idiopathic pulmonary fibrosis (IPF) than in the general population; the relative risk of lung cancer in such patients ranges from 6 to $17 \%[1,2]$. In the general population, the likelihood of a new primary lung cancer developing after complete resection for an initial lung cancer has been reported to be $1 \%$ to $2 \%$ per patient per year $[3,4]$. On the other hand, in patients with IPF, the cumulative rate of developing lung cancer has been reported to increase as the duration of follow-up

\footnotetext{
* Correspondence: seisato@med.niigata-u.ac.jp

${ }^{1}$ Division of Thoracic and Cardiovascular Surgery, Niigata University Graduate School of Medical and Dental Sciences, 1-757 Asahimachi-dori, Chuo-ku, Niigata-shi, Niigata 951-8510, Japan

Full list of author information is available at the end of the article
}

increased $(3.3 \%, 15.4 \%$, and $54.7 \%$ at 1,5 , and 10 years, respectively) [5].

Thoracic surgeons, as well as medical and radiation oncologists, must often make difficult decisions in treating lung cancer patients with IPF because of the poor prognosis of IPF itself and the complications, such as acute exacerbation (AE), which arise after each intervention [5-9]. Several previous studies demonstrated a median survival time of 2 to 3 years after diagnosis in patients with IPF [10-14]. Sato and colleagues [15] reported that $9.3 \%$ of lung cancer patients with IPF developed $\mathrm{AE}$ after pulmonary resection. To estimate the risk of surgery, they proposed a risk score using clinical characteristics and surgical procedures. However, repeated surgical intervention was not included as a risk factor. With regard to the outcome of surgical intervention,

(c) The Author(s). 2018 Open Access This article is distributed under the terms of the Creative Commons Attribution 4.0 International License (http://creativecommons.org/licenses/by/4.0/), which permits unrestricted use, distribution, and 
several studies $[9,16,17]$ reported 5-year survival rates of about $40 \%$ to $60 \%$ for stage I patients; therefore, surgical treatment for lung cancer with concomitant IPF might not be an absolute contraindication, as long as the patients are carefully selected. For lung cancer patients with IPF who undergo surgical interventions, many challenging problems, such as AE of IPF and high rates of second and third primary cancers, have been cited; however, to the best of our knowledge, there have been no studies focusing on the incidence of postoperative AE of IPF and the long-term outcome after a second pulmonary resection. Thus, the purpose of this study was to evaluate the outcomes and risks after a second pulmonary resection and to elucidate the implications of surgical interventions in lung cancer patients with IPF.

\section{Methods}

The medical records of all lung cancer patients admitted from 2001 to 2015 to the Division of Thoracic and Cardiovascular Surgery at Niigata University Hospital and the Department of Thoracic Surgery at Nishi-Niigata Chuo National Hospital were retrospectively reviewed; patients diagnosed with IPF before surgical treatment for lung cancer were identified. The eligibility criteria for surgical resection of lung cancer with IPF were: a resting partial pressure of arterial oxygen $>60 \mathrm{mmHg}$; predicted postoperative forced expiratory volume in $1 \mathrm{~s}>1.0 \mathrm{~L}$; clinically stable and symptomless IPF; and complete resection possible. Of a total of 108 patients enrolled in this study, 17 (15.7\%) with IPF developed second primary lung cancers. Thirteen of these patients underwent a second pulmonary resection, 2 patients received radiotherapy, 1 patient received chemotherapy, and 1 patient had best supportive care. The institutional review board approved this study (Niigata University, 2302) and waived the requirement for informed consent because the study was a retrospective review.

Radiologic assessment of the preoperative conventional chest computed tomography (CT) or high-resolution CT (HRCT) of all patients was performed to confirm the following criteria for IPF: 1) CT patterns compatible with IPF, as proposed by the American Thoracic Society and the European Respiratory Society [18], with bilateral reticular opacities and/or honeycombing predominant in the peripheral, subpleural, and basal locations; and 2) absence of known causes of pulmonary fibrosis, such as hypersensitivity pneumonitis, pneumoconiosis, sarcoidosis, eosinophilic pneumonia, lymphangioleiomyomatosis, drug-induced lung disease, and collagen vascular disease. One thoracic radiologist (HI) and one thoracic surgeon (SS) who were blinded to the clinical data evaluated the preoperative chest CT scans.

The medical records were reviewed to obtain the: demographic and clinical characteristics; chest CT scan findings; pulmonary function test results, including percent vital capacity (\%VC) and percent forced expiratory volume in one second (FEV1\%); surgical procedure; histologic findings; morbidity within 30 days of surgery; postoperative AE of IPF; and survival. AE was defined as: 1) onset within 30 days after pulmonary resection; 2) increasing respiratory distress; 3) newly developed fibrosis, ground glass opacity, or infiltrates on chest radiograph; 4) decrease in the resting partial pressure of arterial oxygen $>10 \mathrm{mmHg}$; and 5) the absence of heart failure or infectious lung disease [19]. A recently reported scoring system was used to assess the 30-day risk of $\mathrm{AE}$ onset after pulmonary resection in lung cancer patients with interstitial lung disease (ILD) based on seven risk factors, including a history of AE of ILD, preoperative steroid use, elevated serum sialylated carbohydrate antigen, KL-6 level, surgical procedure, usual interstitial pneumonia (UIP) pattern on CT scan, male sex, and low $\%$ VC [15].

Pathologic cancer stage was determined using the 7th edition of the International Union Against Cancer tumor-node-metastasis staging system [20]. Information was obtained for all survivors, either during office visits or by telephone interviews with the patient or a relative. The criteria for the diagnosis of multiple primary lung cancers were those described by Martini and Melamed [21] in 1975: 1) different histology or 2) same histology, if the disease-free interval between the two lesions was at least 2 years or development of a new neoplasm from an in situ carcinoma and occurrence of the second tumor in a different lobe or lung, provided that extrapulmonary metastases and lymphatic involvement common to both tumors were excluded. Tumors were designated as 'synchronous' when detected or resected simultaneously and as 'metachronous' when the second tumor was found some time later.

\section{Statistical analyses}

The patients' characteristics are expressed as counts and proportions; categorical variables were compared using the chi-squared test or Fisher's exact test if there were 5 or fewer observations in a cohort. The Mann-Whitney $U$-test was used to compare quantitative parameters. Disease-free survival (DFS) was defined as the time from surgery to documented clinical progression or death. Overall survival (OS) was defined as the time from surgery to death. Prognosis was analyzed using the Kaplan-Meier method with the log-rank test. Differences were considered significant if the $P$-value was less than 0.05 . All statistical analyses were performed using SPSS for Windows Version 22.0 (SPSS, Inc., Chicago, IL, USA). 


\section{Results}

\section{Patients' characteristics}

A total of 108 patients were diagnosed as having IPF based on conventional CT or HRCT findings, and, of them, 17 developed second primary lung cancers. Thirteen patients underwent repeated surgery, and 4 patients did not. The characteristics of the 13 patients are shown in Table 1, and those of the 4 patients are in Additional file 1: Table S1. The median interval between the initial surgery and the second surgery was 2 months (range, 1-3 months) in synchronous tumors, and 26 months (range, 8-68 months) in metachronous tumors. The study group included 11 men and 2 women. The mean age of the patients at the second surgery was

Table 1 Characteristics of patients

\begin{tabular}{|c|c|}
\hline Variable $^{a}$ & Total $=13$ \\
\hline \multicolumn{2}{|l|}{ Age, years } \\
\hline at initial surgery & $70.2 \pm 8.4$ \\
\hline at second surgery & $71.6 \pm 8.6$ \\
\hline \multicolumn{2}{|l|}{ Sex } \\
\hline male & 11 \\
\hline female & 2 \\
\hline \multicolumn{2}{|l|}{ Time interval in months, median (range) } \\
\hline synchronous & $2(1-3)$ \\
\hline metachronous & $26(8-68)$ \\
\hline \multicolumn{2}{|l|}{ Type of multiple cancers } \\
\hline synchronous & 6 \\
\hline metachronous & 7 \\
\hline \multicolumn{2}{|l|}{ Smoking history } \\
\hline PY $<30$ & 2 \\
\hline PY $\geq 30$ & 11 \\
\hline \multicolumn{2}{|l|}{ FEV1\%, mean } \\
\hline at initial surgery & $79.2 \pm 6.8$ \\
\hline at second surgery & $84.5 \pm 7.7$ \\
\hline \multicolumn{2}{|l|}{$\% \mathrm{VC}$, mean } \\
\hline at initial surgery & $104.4 \pm 16.1$ \\
\hline at second surgery & $76.4 \pm 19.7$ \\
\hline \multicolumn{2}{|l|}{$\mathrm{KL}-6(\mathrm{U} / \mathrm{ml})$, mean } \\
\hline at initial surgery & $693.8 \pm 318.4$ \\
\hline at second surgery & $706.8 \pm 377.2$ \\
\hline \multicolumn{2}{|l|}{ AE risk score (initial/second) } \\
\hline Low risk/Low risk & 3 \\
\hline Low risk/Intermediate risk & 1 \\
\hline Intermediate risk/Low risk & 8 \\
\hline Intermediate risk/Intermediate risk & 1 \\
\hline
\end{tabular}

${ }^{a}$ Categorical data are expressed as numbers, and continuous data are expressed as means \pm standard deviation

PY pack years, FEV1 forced expiratory volume in $1 \mathrm{~s}, V C$ vital capacity, KL-6 sialylated carbohydrate antigen $\mathrm{KL}-6, A E$ acute exacerbation
$71.6 \pm 8.6$ years (range, $55-80$ years). Six patients had synchronous tumors, and 7 patients had metachronous tumors. A total of 11 of 13 patients (84.6\%) were heavy smokers ( $\geq 30$ pack years). The mean $\%$ VC was $104.4 \% \pm$ $16.1 \%$ before the initial surgery and $76.4 \% \pm 19.7 \%$ before the second surgery. Regarding the AE risk score [15], 9 patients had intermediate risk and 4 patients had low risk at the initial surgery, but only 2 patients had intermediate risk at the second surgery. During both perioperative periods, IPF prophylaxis, such as steroids, sivelestat sodium hydrate, pirfenidone, and so on, was not given.

\section{Tumor location and type of surgical procedure}

The location of the tumors was in the lower lobe in 9 patients at the initial surgery and in 8 patients at the second surgery. Of the 13 patients, 8 patients $(61.5 \%)$ underwent lobectomy, 2 patients $(15.4 \%)$ underwent segmentectomy, and 3 patients (23.1\%) underwent wedge resection at the initial surgery. At the second surgery, 10 patients $(76.9 \%)$ underwent wedge resection, and 3 patients $(23.1 \%)$ underwent segmentectomy; none of the patients underwent lobectomy (Table 2).

Table 2 Location, surgical procedure, histology, and stage at initial and second surgeries

\begin{tabular}{|c|c|c|}
\hline Variable & Initial No. (\%) & Second No. (\%) \\
\hline \multicolumn{3}{|l|}{ Tumor location } \\
\hline Upper & $4(30.8)$ & $5(38.5)$ \\
\hline Lower & $9(69.2)$ & $8(61.5)$ \\
\hline \multicolumn{3}{|l|}{ Surgical procedure } \\
\hline Wedge & $3(23.1)$ & $10(76.9)$ \\
\hline Segmentectomy & $2(15.4)$ & $3(23.1)$ \\
\hline Lobectomy & $8(61.5)$ & $0(0)$ \\
\hline \multicolumn{3}{|c|}{ Lymph node dissection } \\
\hline None & $3(23.1)$ & $12(92.3)$ \\
\hline Hilum & $1(7.7)$ & $0(0)$ \\
\hline Mediastinum & $9(69.2)$ & $1(7.7)$ \\
\hline \multicolumn{3}{|l|}{ Histology } \\
\hline $\mathrm{Ad}$ & $3(23.1)$ & $3(23.1)$ \\
\hline $\mathrm{Sq}$ & $8(61.5)$ & $8(61.5)$ \\
\hline $\mathrm{Ad}-\mathrm{Sq}$ & $1(7.7)$ & $2(15.4)$ \\
\hline $\mathrm{Sm}$ & $1(7.7)$ & $0(0)$ \\
\hline \multicolumn{3}{|l|}{ Pathological stage } \\
\hline $\mid A$ & $3(23.1)$ & $4(30.8)$ \\
\hline IB & $5(38.5)$ & $9(69.2)$ \\
\hline$\| \mathrm{A}$ & $2(15.4)$ & $0(0)$ \\
\hline$\| \mathrm{B}$ & $1(7.7)$ & $0(0)$ \\
\hline$\| I A$ & $2(15)$. & $0(0)$ \\
\hline
\end{tabular}

$N D$ node dissection, $A d$ adenocarcinoma, $S q$ squamous cell carcinoma, $A d-S q$ adenosquamous cell carcinoma, $\mathrm{Sm}$ small cell carcinoma 


\section{Histologic diagnoses and tumor staging}

As shown in Table 2, squamous cell carcinoma was the most common finding at the initial and second surgeries ( $n=8,61.5 \%$, for both). Both initial and second tumors were squamous cell carcinoma in 4 patients and adenocarcinoma in 1 patient.

The pathologic stage of the initial tumor was stage I in 8 patients (61.5\%), stage II in 3 patients $(23.1 \%)$, and stage IIIA in 2 patients (15.4\%). Ten patients underwent lymph node dissection.

At the second surgery, the clinical stage of the second tumor was stage IA in 12 patients and stage IB in only 1 patient. However, the pathologic stage of the second tumor was stage IA in 4 patients and stage IB in 9 patients. In all 8 cases, the reason for upstaging from IA to IB was pleural invasion. However, 12 patients $(92.3 \%)$ underwent only sublobar resection without lymph node dissection.

\section{Postoperative acute exacerbation}

At initial surgery, 6 (5.6\%) of 108 patients developed postoperative AE of IPF (Fig. 1). Table 3 shows the patients who developed postoperative AE of IPF at the initial or second surgery. Comparing the 6 patients at the

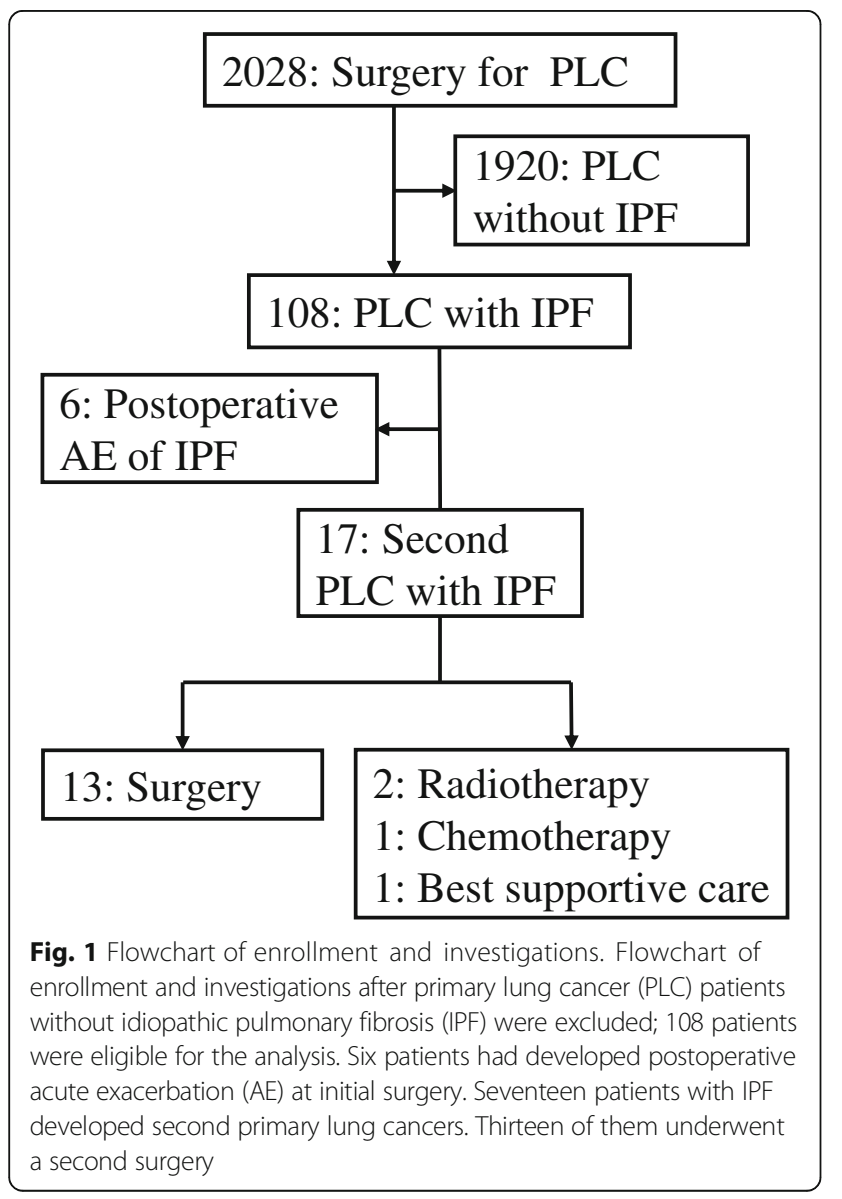

Table 3 Clinical characteristics of patients with postoperative acute exacerbation after initial and second surgeries

\begin{tabular}{|c|c|c|c|}
\hline Variable $^{a}$ & Initial $N=6$ & Second $N=3$ & $p$ Value $^{\mathrm{b}}$ \\
\hline Age, years & $71.3 \pm 8.2$ & $72.7 \pm 8.4$ & 1.000 \\
\hline \multicolumn{4}{|l|}{ Sex } \\
\hline Male & 6 & 3 & \multirow[t]{2}{*}{ NA } \\
\hline Female & 0 & 0 & \\
\hline Smoking history (PY), mean & $50.8 \pm 8.3$ & $78.7 \pm 43.6$ & 0.381 \\
\hline FEV1\%, mean & $81.9 \pm 5.2$ & $87.5 \pm 11.2$ & 0.393 \\
\hline$\%$ VC, mean & $78.5 \pm 9.8$ & $64.4 \pm 19.7$ & 0.262 \\
\hline $\mathrm{KL}-6(\mathrm{U} / \mathrm{ml})$, mean & $1204.4 \pm 638.4$ & $606.3 \pm 279.2$ & 0.143 \\
\hline AE risk score, mean & $12.8 \pm 1.2$ & $9.0 \pm 1.7$ & 0.024 \\
\hline Low risk & 0 & 2 & \\
\hline Intermediate risk & 6 & 1 & \\
\hline \multicolumn{4}{|l|}{ Tumor location } \\
\hline Upper & 2 & 0 & \multirow[t]{2}{*}{0.417} \\
\hline Lower & 4 & 3 & \\
\hline \multicolumn{4}{|l|}{ Surgical procedure } \\
\hline Wedge & 0 & 1 & \multirow[t]{3}{*}{$0.333^{c}$} \\
\hline Segmentectomy & 1 & 2 & \\
\hline Lobectomy & 5 & 0 & \\
\hline \multicolumn{4}{|l|}{ Histology } \\
\hline Ad & 2 & 1 & \multirow[t]{3}{*}{0.301} \\
\hline $\mathrm{Sq}$ & 4 & 1 & \\
\hline $\mathrm{Ad}-\mathrm{Sq}$ & 0 & 1 & \\
\hline \multicolumn{4}{|l|}{ Pathological stage } \\
\hline IA & 0 & 1 & \multirow[t]{4}{*}{0.392} \\
\hline $\mathrm{IB}$ & 4 & 2 & \\
\hline$\| A$ & 1 & 0 & \\
\hline$\| \mathrm{B}$ & 1 & 0 & \\
\hline
\end{tabular}

${ }^{a}$ Categorical data are expressed as numbers, and continuous data are expressed as means \pm standard deviation

${ }^{b}$ Values of $p<0.05$ are significant

'Value is a comparison between wedge vs. segmentectomy and lobectomy $N A$ not available, $P Y$ pack year, FEV1 forced expiratory volume in $1 \mathrm{~s}, V C$ vital capacity, $K L-6$ sialylated carbohydrate antigen $\mathrm{KL}-6, A E$ acute exacerbation, $A d$ adenocarcinoma, $S q$ squamous cell carcinoma, $A d-S q$ adenosquamous cell carcinoma

initial surgery and the 3 patients at the second surgery, the AE risk score was significantly lower for the second surgery cohort than for the initial surgery cohort $(p=0.024)$.

Comparison of the patients according to the presence or absence of postoperative AE of IPF at the second surgery is shown in Table 4. In this series, 3 patients developed and died of $\mathrm{AE}$ in the postoperative period (Table 5). The rate of \%VC decrease was significantly higher in patients with $\mathrm{AE}$ than in patients without $\mathrm{AE}$ $(p=0.011)$. In all 3 patients with $\mathrm{AE}$, tumor location was the lower lobe at the initial and second surgeries. On the 
Table 4 Clinical characteristics of patients with and without acute exacerbation after the second surgery

\begin{tabular}{|c|c|c|c|}
\hline Variable $^{a}$ & $\begin{array}{l}\text { With AE } \\
(n=3)\end{array}$ & $\begin{array}{l}\text { Without AE } \\
(n=10)\end{array}$ & $p$ Value $^{b}$ \\
\hline \multicolumn{4}{|l|}{ Sex } \\
\hline Male & 3 & 8 & \multirow[t]{2}{*}{0.577} \\
\hline Female & 0 & 2 & \\
\hline \multicolumn{4}{|l|}{ Type of multiple cancer } \\
\hline Synchronous & 1 & 5 & \multirow[t]{2}{*}{0.563} \\
\hline Metachronous & 2 & 5 & \\
\hline \multicolumn{4}{|l|}{ Smoking history } \\
\hline$P Y<30$ & 0 & 2 & \multirow[t]{2}{*}{0.577} \\
\hline$P Y \geq 30$ & 3 & 8 & \\
\hline FEV1\%, mean & $87.5 \pm 11.2$ & $83.3 \pm 6.6$ & 0.455 \\
\hline$\% \mathrm{VC}$, mean & $64.4 \pm 19.7$ & $80.9 \pm 19.0$ & 0.234 \\
\hline $\begin{array}{l}\text { Rate of \%VC decrease from } \\
\text { initial surgery, mean }\end{array}$ & $35.9 \pm 11.7$ & $20.1 \pm 5.6$ & 0.011 \\
\hline KL-6 (U/ml), mean & $596.3 \pm 270.8$ & $743.5 \pm 413.8$ & 0.583 \\
\hline \multicolumn{4}{|l|}{ AE risk score } \\
\hline Low risk & 2 & 9 & \multirow[t]{2}{*}{0.423} \\
\hline Intermediate risk & 1 & 1 & \\
\hline \multicolumn{4}{|c|}{ Combination of tumor location (initial/second) } \\
\hline Lower/Lower & 3 & 3 & \multirow[t]{2}{*}{0.070} \\
\hline Other & 0 & 7 & \\
\hline \multicolumn{4}{|c|}{ Combination of surgical procedure (initial/second) } \\
\hline Wedge/Wedge & 0 & 2 & \multirow[t]{3}{*}{0.296} \\
\hline Lobectomy/Sublobar & 3 & 5 & \\
\hline Other & 0 & 3 & \\
\hline
\end{tabular}

${ }^{a}$ Categorical data are expressed as numbers, and continuous data are expressed as means \pm standard deviation

${ }^{b}$ Values of $p<0.05$ are significant

$A E$ acute exacerbation, $P Y$ pack years, FEV1 forced expiratory volume in $1 \mathrm{~s}, V C$ vital capacity, KL-6 sialylated carbohydrate antigen KL-6

other hand, development of AE was not significantly correlated with sex, types of multiple cancers, smoking history, KL-6, and combination of surgical procedures. Regarding the AE risk score that was proposed by Sato and colleagues at the second surgery [15], there was no significant difference between patients with and without $\mathrm{AE}$. The risk of developing AE after the second surgery was low in 2 of $11(18.2 \%)$ patients and intermediate in 1 of $2(50 \%)$ patients. Over the same time period, the development of $\mathrm{AE}$ of IPF in 4 patients who did not undergo surgical treatment for second primary lung cancer was investigated, and it was found that no patients developed AE of IPF.

\section{Survival}

The median follow-up period after the second surgery was 24.9 months (range, 1.5-54.0 months). The disease-free survival (DFS) rates were $60.6 \%$ at 1 year and $8.7 \%$ at
3 years (Fig. 2a). Overall survival (OS) was $69.2 \%$ at 1 year and $34.6 \%$ at 3 years (Fig. 2b). Regarding the pattern of lung cancer recurrence in 8 patients, 4 patients developed intrathoracic disease (local), and 4 patients developed extrathoracic spread (distant). During the follow-up period, 11 patients $(84.6 \%)$ died, and the most common cause was cancer-related; 7 patients died of recurrent lung cancer, and 1 patient died of additional metachronous lung cancer. The 3 other patients died of AE of IPF. Only 2 patients remained alive; one was free of relapse, while the other had local recurrence. Adjuvant therapy with oral tegafur-uracil after the second surgery was administered in 1 patient with stage IB adenocarcinoma.

\section{Discussion}

The incidence of lung cancer is higher in patients with IPF than in those without IPF. Notably, Fujimoto and colleagues [22] reported a high incidence of second primary lung cancer in patients with IPF.

Lung cancer patients with IPF are more likely to develop severe morbidity and have poor outcomes after pulmonary resection. Considering the high recurrence rate and the poor prognosis for this patient population, operative indicators for major pulmonary resection in patients with lung cancer with IPF remain unclear. Kushibe and colleagues [23] reported that patients with IPF who had postoperative acute lung injury/acute respiratory distress syndrome had a significantly lower preoperative percent forced VC (\%FVC) than those without such complications. IPF patients with a preoperative $\% \mathrm{FVC}<80 \%$ may not have an operative indication for lung cancer, and those with a preoperative $\% \mathrm{FVC} \geq 90 \%$ could have a good operative indication. Fujimoto and colleagues [22] suggested that patients with lung cancer invading the chest wall were excluded from surgery because chest wall resection is associated with major morbidity [24]. Pneumonectomy should be avoided for the same reason.

There have been several reports on the surgical outcomes of lung cancer patients with IPF $[1,7,9,15-17$, $22,23,25]$; however, to the best of our knowledge, the implications of repeated surgery in such patients have not been reported. The present study found a poor prognosis for patients with IPF even after complete repeated resection of lung cancer, with 3-year DFS and OS rates of $8.7 \%$ and $34.6 \%$, respectively.

Recently, a large cohort study by Sato and colleagues [15] reported their derived scoring system for the 30-day risk of developing AE of IPF after pulmonary resection and classified patients into three risk groups (i.e., low, intermediate, and high). In the present study, higher rates of developing postoperative $\mathrm{AE}$ were found than cited in the previous report. According to Sato and colleagues, the predicted $\mathrm{AE}$ 
Table 5 Clinical characteristics of patients with acute exacerbation after the second surgery

\begin{tabular}{|c|c|c|c|}
\hline Variable & Case 1 & Case 2 & Case 3 \\
\hline Sex & Male & Male & Male \\
\hline Age (years) & 77 & 78 & 63 \\
\hline Time interval (months) & 34 & 14 & 3 \\
\hline Type of multiple cancer & Metachronous & Metachronous & Synchronous \\
\hline Smoking history (PY) & 54 & 53 & 129 \\
\hline$\% \mathrm{VC}$ at second surgery & 87.1 & 52.6 & 53.4 \\
\hline Rate of \%VC decrease & 24.3 & 47.6 & 35.7 \\
\hline KL-6 (U/ml) & 284 & 766 & 739 \\
\hline AE risk score & 11 & 8 & 8 \\
\hline Tumor location (initial/second) & Lower/Lower & Lower/Lower & Lower/Lower \\
\hline Surgical procedure (initial/second) & Lobectomy/Segmentectomy & Lobectomy/Wedge & Lobectomy/Wedge \\
\hline Histology (initial/second) & $\mathrm{Sq} / \mathrm{Ad}$ & Sq/Ad-Sq & $\mathrm{Sq} / \mathrm{Sq}$ \\
\hline Pathological stage & $\mid A / B$ & $\mathrm{IB} / \mathrm{B}$ & $|A /| A$ \\
\hline
\end{tabular}

PY pack years, VC vital capacity, KL-6 sialylated carbohydrate antigen KL-6, AE acute exacerbation, Sq squamous cell carcinoma, $A d-S q$ adenosquamous cell carcinoma

incidence was $<10 \%$ [95\% confidence interval (CI): 0-10] in the low risk group and $10-25 \%$ (95\% CI: 8.8-29.7) in the intermediate risk group, though 2 of $11(18.2 \%)$ patients at low risk and 1 of $2(50 \%)$ patients at intermediate risk developed and died of $\mathrm{AE}$ in the present study. The patients who developed postoperative $\mathrm{AE}$ at the initial surgery were compared with those who developed postoperative $\mathrm{AE}$ at the second surgery, and $\mathrm{AE}$ in the second surgery cohort developed with a significantly lower risk score than in the initial surgery cohort. The patients who did not undergo surgical treatment for second primary lung cancers were also examined, and no patients developed AE of IPF. Although the present study sample was very small, repeated surgery for lung cancer in patients with IPF could be a risk factor for AE.
The etiologic agents of AE of IPF after pulmonary resection remain unclear. Sakamoto and colleagues [26] reported the possible factors contributing to $\mathrm{AE}$ after surgery in patients with IPF: 1) high activity of the disease prior to the surgery; 2) oxygen supplementation at a high concentration during surgery; 3) surgical stress including mechanical ventilation-related lung injury; 4) complicating respiratory infections; 5) postoperative reduction of steroid dose; and 6) medications (anesthesia, anticancer drugs, and so on). Misthos and colleagues [27] investigated the possibility of an association between oxygen radical toxicity and the occurrence of $\mathrm{AE}$ of IPF. They found the following: 1) lung re-expansion after one-lung ventilation (OLV) provoked severe oxidative stress; 2) the degree of oxygen-derived free radicals

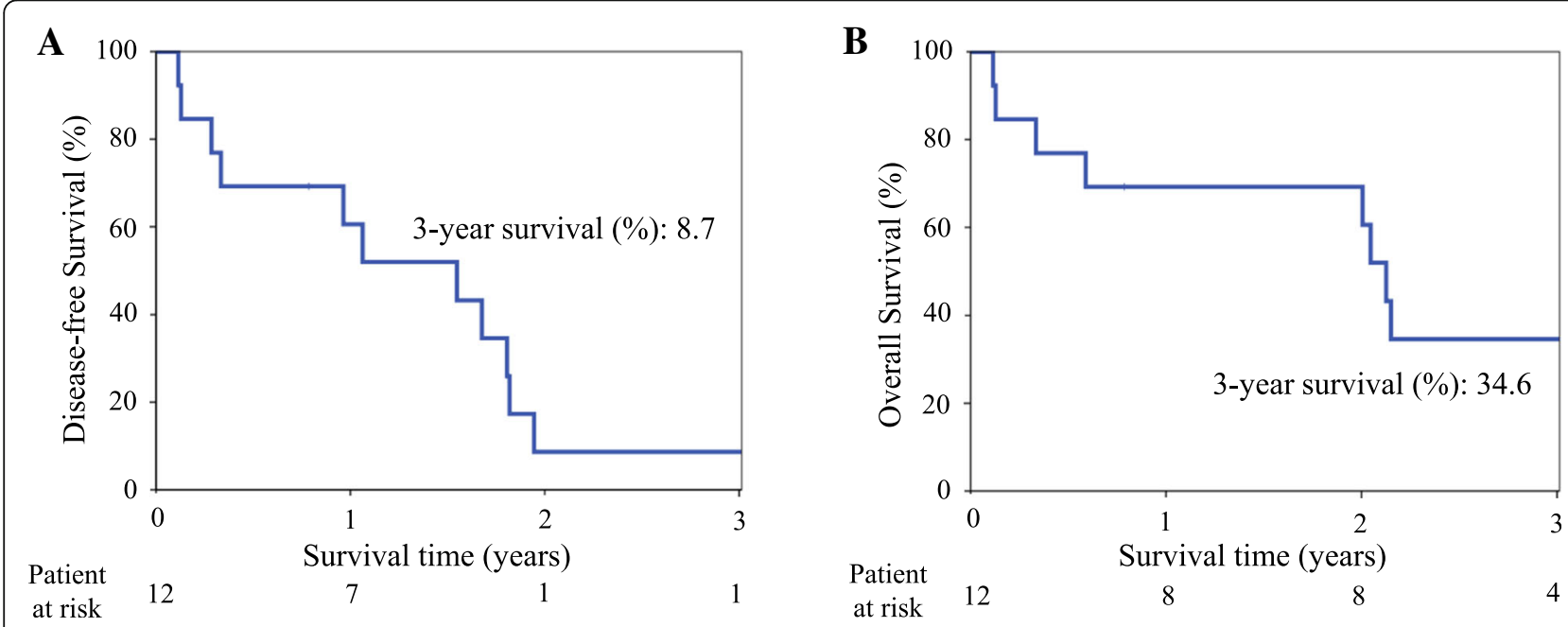

Fig. 2 Outcomes in lung cancer patients with idiopathic pulmonary fibrosis after the second surgery. a The 3-year disease-free survival is $8.7 \%$. b The 3 -year overall survival is $34.6 \%$ 
generated was associated with the duration of OLV; 3) patients with lung cancer had higher production of oxygen-derived free radicals than the normal population; 4) tumor resection removes a large oxidative burden from the organism; 5) mechanical ventilation and surgical trauma are weak free radical generators; and 6) manipulated lung tissue is also a source of oxygen-derived free radicals, not only intraoperatively, but also for several hours later.

The present analysis showed that the rate of \% VC decrease was significantly higher in patients with $\mathrm{AE}$ than in those without $\mathrm{AE}$. \% VC has been considered a reliable marker of fibrotic change [11, 13], and some previous studies $[23,25]$ reported that $\% \mathrm{VC}$ had a significant and independent association with the development of AE. In the present study, the \%VC of 1 patient with $\mathrm{AE}$ was not lower than $80 \%$, but the rate of $\% \mathrm{VC}$ decrease was 24.3\%. Therefore, the AE incidence at the second surgery for lung cancer in patients with IPF is associated not only with a low \%VC, but also with a high rate of $\% \mathrm{VC}$ decrease. Also, among the pulmonary function tests, \%DLCO has been considered a survival predictor $[7,28]$ and a reliable indicator of fibrotic change [12, 13, 29]. However, it was not included in the present study because the values of only 3 of 13 patients were available.

In the present study, the reason for the poor prognosis was a high rate of cancer recurrence, aside from development of AE. Although all patients were clinical stage IA or IB at the second surgery, 8 of 10 patients had cancer recurrence, except those who died of AE. Saito and colleagues [16] reported that the 5-year survival of lung cancer stage IA patients with IPF was $54.2 \%$. Watanabe and colleagues [9] reported a 5-year survival of $61.6 \%$ after pulmonary resection for patients with stage I. Sato and colleagues [17] reported that the 5-year survival rates were $59 \%$ and $42 \%$ for pathologic stages IA and IB, respectively. Watanabe and colleagues [9] and Okamoto and colleagues [7] suggested that the frequency of cancer recurrence was higher in patients with IPF than in those without. Sato and colleagues [17] reported that recurrence was the main cause of death and posed a risk that was about twice as high as that of respiratory disorders; they underscored the importance of oncologic control for survival. In the present study, sublobar resection was performed in all patients, and lymph node dissection was performed in only 1 patient at the second surgery. Sato and colleagues [17] noted that stage IA patients who underwent wedge resection had a prolonged survival and were less likely to develop AE of IPF, but they had a higher cancer recurrence rate than patients who underwent lobectomy. Furthermore, patients who underwent segmentectomy had less favorable oncologic outcomes than patients who underwent lobectomy. At the second surgery, accurate pathologic staging might not be possible because lymph node dissection was not performed in almost all patients. Needless to say, it was necessary to consider the influence of lung cancer recurrence not only in the second surgery, but also at the initial surgery. Actually, of the 5 of 8 patients who developed recurrence, 3 were stage II and 2 were stage III at the time of the initial surgery.

With regard to distinguishing multiple primary lung cancers from primary lung cancer with intrapulmonary metastasis, the possible effects of multiple lung tumors, as defined by Martini and Melamed [21], were considered. Although it is important to distinguish a second primary cancer from local recurrence or metastatic disease, this is sometimes difficult and even impossible. Girard and colleagues [30] considered that biologic examinations could be performed, assuming that the independent tumor clones harbor distinct mutations. In the present study, the same histologic diagnoses at the initial and second surgeries were seen in 4 patients with squamous cell carcinoma and in 1 patient with adenocarcinoma. Among them, 2 patients with squamous cell carcinoma and the patient with adenocarcinoma were investigated, but they were negative for epidermal growth factor receptor mutation at both the initial and second surgeries.

Squamous cell carcinoma had a higher prevalence than the other histopathological types among the patients with IPF in the present study, consistent with the previous reports. The cause of the high prevalence of squamous cell carcinoma in IPF patients remains unclear. Song and colleagues [31] found many foci of squamous metaplasia in honeycombing epithelium, and Hironaka and Fukuyama [32] reported that IPF patients with lung cancer showed more frequent foci of squamous metaplasia than IPF patients without lung cancer. Calabrese and colleagues [33] reported the overexpression of squamous cell antigen, a serine protease inhibitor typically expressed by dysplastic and neoplastic cells of epithelial origin, more often in squamous cell tumors, in IPF. These pathological findings support the notion that IPF may be a precursor to the development of squamous cell carcinoma.

\section{Limitations}

The present study had some limitations. First, only 3 patients developed AE of IPF at the second surgery; this number could be insufficient to predict the tendency for developing AE. Second, the present study included only IPF patients who underwent surgical procedures for multiple primary lung cancers and did not include IPF patients with multiple primary lung cancers who did not undergo surgical intervention. Therefore, the implications of a second surgery for lung cancer patients with IPF remain unclear. Third, this was a retrospective, two-institution study with a limited sample size. Further studies should be conducted to identify who among the patients with IPF who had undergone a first pulmonary resection for lung cancer could benefit from interventions, including surgery, chemotherapy, and radiotherapy, for the multiple primary lung cancers. 


\section{Conclusions}

Postoperative development of AE and the long-term survival of patients with a second primary lung cancer with IPF who underwent repeated surgery were investigated. The main cause of their poor prognosis was cancer death, possibly related to sublobar resection. Repeated surgery for patients with lung cancer and concomitant IPF could increase the risk of $\mathrm{AE}$ development despite limited surgery. The rate of \% VC decrease might be correlated with the incidence of $\mathrm{AE}$. Although these results demonstrated that surgical intervention for multiple primary lung cancers might be contraindicated in patients with IPF, selection of patients who may benefit from such treatment is very important. To confirm these findings, a large, long-term, multi-center surveillance study will be required.

\section{Additional file}

Additional file 1: Table S1. Clinical characteristics of patients without surgical treatment for second primary lung cancer. (DOCX $13 \mathrm{~kb}$ )

\section{Abbreviations}

\%VC: Percent vital capacity; AE: Acute exacerbation; Cl: Confidence interval; $\mathrm{CT}$ : Computed tomography; FEV1\%: Percent forced expiratory volume in one second; HRCT: High-resolution computed tomography; ILD: Interstitial lung disease; IPF: Idiopathic pulmonary fibrosis; UIP: Usual interstitial pneumonia

\section{Availability of data and materials}

The datasets used and/or analyzed during the current study are available from the corresponding authors on reasonable request.

\section{Authors' contributions \\ SS: contributed to development of the study concept, data collection, data analysis, manuscript drafting including revision, and final manuscript approval. YS, TG, AK, TK, and TW: contributed to performing data collection, data analysis, and final manuscript approval. $\mathrm{HI}$ and SS: contributed to the analysis of the CT examination findings. TM: contributed to development of the study concept, data analysis, manuscript drafting including revision, and final manuscript approval. All authors read and approved the final manuscript.}

\section{Ethics approval and consent to participate}

The study was approved by the ethics committee of the Niigata University (No. 2302), and the requirement for informed consent was waived because the study was a retrospective review.

\section{Consent for publication}

Not applicable.

\section{Competing interests}

The authors declare that they have no competing interests.

\section{Publisher's Note}

Springer Nature remains neutral with regard to jurisdictional claims in published maps and institutional affiliations.

\section{Author details}

${ }^{1}$ Division of Thoracic and Cardiovascular Surgery, Niigata University Graduate School of Medical and Dental Sciences, 1-757 Asahimachi-dori, Chuo-ku, Niigata-shi, Niigata 951-8510, Japan. ²Department of Radiology and Radiation Oncology, Niigata University Graduate School of Medical and Dental Sciences, Niigata, Japan. ${ }^{3}$ Department of Thoracic Surgery, National Hospital Organization Nishi-Niigata Chuo National Hospital, Niigata, Japan.
Received: 23 February 2018 Accepted: 1 August 2018

Published online: 10 August 2018

\section{References}

1. Kumar P, Goldstraw P, Yamada K, Nicholson AG, Wells AU, Hansell DM, Dubois RM, Ladas G. Pulmonary fibrosis and lung cancer: risk and benefit analysis of pulmonary resection. J Thorac Cardiovasc Surg. 2003;125(6):1321-7.

2. Raghu G, Nyberg F, Morgan G. The epidemiology of interstitial lung disease and its association with lung cancer. Br J Cancer. 2004;91(Suppl 2):S3-10.

3. Johnson BE. Second lung cancers in patients after treatment for an initial lung cancer. J Natl Cancer Inst. 1998;90(18):1335-45.

4. Rubins J, Unger M, Colice GL, American College of Chest P. Follow-up and surveillance of the lung cancer patient following curative intent therapy: ACCP evidence-based clinical practice guideline (2nd edition). Chest. 2007; 132(3 Suppl):355S-67S.

5. Ozawa Y, Suda T, Naito T, Enomoto N, Hashimoto D, Fujisawa T, Nakamura Y, Inui N, Nakamura H, Chida K. Cumulative incidence of and predictive factors for lung cancer in IPF. Respirology. 2009;14(5):723-8.

6. Isobe K, Hata Y, Sakamoto S, Takai Y, Shibuya K, Homma S. Clinical characteristics of acute respiratory deterioration in pulmonary fibrosis associated with lung cancer following anti-cancer therapy. Respirology. 2010;15(1):88-92.

7. Okamoto T, Gotoh M, Masuya D, Nakashima T, Liu D, Kameyama K, Ishikawa $\mathrm{S}$, Yamamoto $\mathrm{Y}$, Huang $\mathrm{CL}$, Yokomise $\mathrm{H}$. Clinical analysis of interstitial pneumonia after surgery for lung cancer. Jpn J Thorac Cardiovasc Surg. 2004;52(7):323-9.

8. Turner-Warwick M, Lebowitz M, Burrows B, Johnson A. Cryptogenic fibrosing alveolitis and lung cancer. Thorax. 1980;35(7):496-9.

9. Watanabe A, Higami T, Ohori S, Koyanagi T, Nakashima S, Mawatari T. Is lung cancer resection indicated in patients with idiopathic pulmonary fibrosis? J Thorac Cardiovasc Surg. 2008;136(5):1357-63. 1363 e1351-1352

10. Bjoraker JA, Ryu JH, Edwin MK, Myers JL, Tazelaar HD, Schroeder DR, Offord KP. Prognostic significance of histopathologic subsets in idiopathic pulmonary fibrosis. Am J Respir Crit Care Med. 1998;157(1):199-203.

11. Ley B, Collard HR, King TE Jr. Clinical course and prediction of survival in idiopathic pulmonary fibrosis. Am J Respir Crit Care Med. 2011;183(4):431-40.

12. Nicholson AG, Colby TV, du Bois RM, Hansell DM, Wells AU. The prognostic significance of the histologic pattern of interstitial pneumonia in patients presenting with the clinical entity of cryptogenic fibrosing alveolitis. Am J Respir Crit Care Med. 2000;162(6):2213-7.

13. Raghu G, Collard HR, Egan JJ, Martinez FJ, Behr J, Brown KK, Colby TV, Cordier JF, Flaherty KR, Lasky JA, et al. An official ATS/ERS/JRS/ALAT statement: idiopathic pulmonary fibrosis: evidence-based guidelines for diagnosis and management. Am J Respir Crit Care Med. 2011;183(6):788-824.

14. Rudd RM, Prescott RJ, Chalmers JC, Johnston ID, Fibrosing Alveolitis Subcommittee of the Research Committee of the British thoracic S. British Thoracic Society study on cryptogenic fibrosing alveolitis: response to treatment and survival. Thorax. 2007;62(1):62-6.

15. Sato T, Teramukai S, Kondo H, Watanabe A, Ebina M, Kishi K, Fujii Y, Mitsudomi T, Yoshimura M, Maniwa T, et al. Impact and predictors of acute exacerbation of interstitial lung diseases after pulmonary resection for lung cancer. J Thorac Cardiovasc Surg. 2014;147(5):1604-11. e1603

16. Saito Y, Kawai Y, Takahashi N, Ikeya T, Murai K, Kawabata Y, Hoshi E. Survival after surgery for pathologic stage IA non-small cell lung cancer associated with idiopathic pulmonary fibrosis. Ann Thorac Surg. 2011;92(5):1812-7.

17. Sato T, Watanabe A, Kondo H, Kanzaki M, Okubo K, Yokoi K, Matsumoto K, Marutsuka T, Shinohara $H$, Teramukai S, et al. Long-term results and predictors of survival after surgical resection of patients with lung cancer and interstitial lung diseases. J Thorac Cardiovasc Surg. 2015;149(1):64-9. 70 e61-62

18. American Thoracic S, European Respiratory S. American Thoracic Society/ European Respiratory Society international multidisciplinary consensus classification of the idiopathic interstitial pneumonias. This joint statement of the American Thoracic Society (ATS), and the European Respiratory Society (ERS) was adopted by the ATS board of directors, June 2001 and by the ERS executive committee, June 2001. Am J Respir Crit Care Med. 2002; 165(2):277-304.

19. Akira M, Hamada H, Sakatani M, Kobayashi C, Nishioka M, Yamamoto S. C findings during phase of accelerated deterioration in patients with idiopathic pulmonary fibrosis. AJR Am J Roentgenol. 1997;168(1):79-83.

20. Goldstraw P, Crowley J, Chansky K, Giroux DJ, Groome PA, Rami-Porta R, Postmus PE, Rusch V, Sobin L, International Association for the Study of Lung Cancer international staging $C_{\text {, et }}$ al. The IASLC lung Cancer staging 
project: proposals for the revision of the TNM stage groupings in the forthcoming (seventh) edition of the TNM classification of malignant tumours. J Thorac Oncol. 2007;2(8):706-14.

21. Martini N, Melamed MR. Multiple primary lung cancers. J Thorac Cardiovasc Surg. 1975;70(4):606-12.

22. Fujimoto T, Okazaki T, Matsukura T, Hanawa T, Yamashita N, Nishimura K, Kuwabara M, Matsubara Y. Operation for lung cancer in patients with idiopathic pulmonary fibrosis: surgical contraindication? Ann Thorac Surg. 2003;76(5):1674-8. discussion 1679

23. Kushibe K, Kawaguchi T, Takahama M, Kimura M, Tojo T, Taniguchi S. Operative indications for lung cancer with idiopathic pulmonary fibrosis. Thorac Cardiovasc Surg. 2007;55(8):505-8.

24. Burkhart HM, Allen MS, Nichols FC 3rd, Deschamps C, Miller DL, Trastek VF, Pairolero PC. Results of en bloc resection for bronchogenic carcinoma with chest wall invasion. J Thorac Cardiovasc Surg. 2002:123(4):670-5.

25. Shintani Y, Ohta M, Iwasaki T, Ikeda N, Tomita E, Kawahara K, Ohno Y. Predictive factors for postoperative acute exacerbation of interstitial pneumonia combined with lung cancer. Gen Thorac Cardiovasc Surg. 2010;58(4):182-5.

26. Sakamoto S, Homma S, Mun M, Fujii T, Kurosaki A, Yoshimura K. Acute exacerbation of idiopathic interstitial pneumonia following lung surgery in 3 of 68 consecutive patients: a retrospective study. Intern Med. 2011; 50(2):77-85.

27. Misthos P, Katsaragakis S, Milingos N, Kakaris S, Sepsas E, Athanassiadi K, Theodorou D, Skottis I. Postresectional pulmonary oxidative stress in lung cancer patients. The role of one-lung ventilation. Eur J Cardiothorac Surg. 2005:27(3):379-82. discussion 382-373

28. Ferguson MK, Reeder LB, Mick R. Optimizing selection of patients for major lung resection. J Thorac Cardiovasc Surg. 1995;109(2):275-81. discussion 281-273

29. Cherniack RM, Colby TV, Flint A, Thurlbeck WM, Waldron JA Jr, Ackerson L, Schwarz MI, King TE Jr. Correlation of structure and function in idiopathic pulmonary fibrosis. Am J Respir Crit Care Med. 1995;151(4):1180-8.

30. Girard N, Deshpande C, Azzoli CG, Rusch WW, Travis WD, Ladanyi M, Pao W. Use of epidermal growth factor receptor/Kirsten rat sarcoma 2 viral oncogene homolog mutation testing to define clonal relationships among multiple lung adenocarcinomas: comparison with clinical guidelines. Chest. 2010;137(1):46-52.

31. Song DH, Choi IH, Ha SY, Han KM, Lee JJ, Hong ME, Jeon K, Chung MP, Kim J, Han J. Usual interstitial pneumonia with lung cancer: clinicopathological analysis of 43 cases. Korean J Pathol. 2014;48(1):10-6.

32. Hironaka M, Fukayama M. Pulmonary fibrosis and lung carcinoma: a comparative study of metaplastic epithelia in honeycombed areas of usual interstitial pneumonia with or without lung carcinoma. Pathol Int. 1999;49(12): 1060-6.

33. Calabrese F, Lunardi F, Giacometti C, Marulli G, Gnoato M, Pontisso P, Saetta $M$, Valente $M$, Rea $F$, Perissinotto $E$, et al. Overexpression of squamous cell carcinoma antigen in idiopathic pulmonary fibrosis: clinicopathological correlations. Thorax. 2008;63(9):795-802.

Ready to submit your research? Choose BMC and benefit from:

- fast, convenient online submission

- thorough peer review by experienced researchers in your field

- rapid publication on acceptance

- support for research data, including large and complex data types

- gold Open Access which fosters wider collaboration and increased citations

- maximum visibility for your research: over $100 \mathrm{M}$ website views per year

At $\mathrm{BMC}$, research is always in progress.

Learn more biomedcentral.com/submissions 